\title{
TUBERCULOSIS SCREENING IN INMATES AND STAFF OF A NSW JAIL
}

Tim Sladden, North Coast Public Health Unit Jill O'Donnell, Chest Clinic, Grafton Base Hospital Michael Levy, AIDS / Infectious Diseases Branch, NSW Health Department

$\mathbf{T}$ his article reports on a screening survey for tuberculosis (TB) infection in a NSW jail. Its objective was to determine the extent of TB infection and risk factors among inmates.

Prison populations have been identified as having an increased incidence of active TB in overseas studies ${ }^{1}$. The NSW Health Department has identified control of TB as an important public health issue ${ }^{2}$. A major part of the NSW TB control strategy is the identification of high-risk settings for TB transmission, appropriate monitoring of people in these settings and supervised treatment of cases.

Development of multi-drug resistant strains of Mycobacterium tuberculosis and concurrent HIV/TB infection has led to increased concern about TB and the need for implementation of control strategies ${ }^{3}$.

Prison inmates and staff are a mobile population. Introduction of infectious diseases into the prison system can occur at any time. Inmates are frequently moved between jails and remain in detention for variable lengths of time, living in close proximity and sharing cells.

There is little information about the extent of exposure to Mycobacterium tuberculosis in the NSW prison system. A review of TB notifications in NSW undertaken in 1993 revealed no active cases in prison inmates. But no routine monitoring of TB infection has been conducted and there is a need to develop appropriate screening and TB management practices in prisons.

\section{METHODS}

All inmates of Grafton Correctional Centre during June 1993 were invited to have Mantoux tuberculin tests. Prison staff were examined to assess their exposures. Tests were conducted on five days between June 15 and July 5, 1993 . Reactions of $10 \mathrm{~mm}$ or greater in people who had not had a $B C G$, and $15 \mathrm{~mm}$ or greater in vaccinated people, on the third day after the test were regarded as positive. Inmates were interviewed about BCG vaccination status. Those found to be Mantoux positive were offered chest x-rays. Medical notes of inmates were reviewed by staff of the Corrections Health Service for further relevant details.

All information was entered into a database (Epi-Info) for analysis. Individual associations between Mantoux positivity and age, length of time in jail, BCG status, Aboriginality, country of birth, and alcohol and injecting drug use were examined. Logistic regression modelling (SAS) was also used to assess the combined influence of these variables on Mantoux positivity.

\section{RESULTS}

The prison's maximum capacity was 260 inmates and it had a full-time staff of 115 . In all, 140 inmates ( 54 per cent) and 20 staff ( 17 per cent) were screened.

All but two of the screened inmates were male. The age range was $19-69$ years (the mean age was 35 , with a standard deviation of 9.7 years). Only three inmates were positively identified as Aboriginal, but Aboriginality was not specifically ascertained for a further 47 ( 34 per cent). Eighty-two inmates (59 per cent) reported that they were Australian-born, 14 (10 per cent) were known to be born overseas and country of origin was not ascertained for the remaining 44 ( 31 per cent).

Mantoux results were available for all but one of the inmates screened. Of the 140 inmates tested, 66 ( 47 per cent) had a reaction of at least $5 \mathrm{~mm}$ and 47 (34 per cent) were defined as Mantoux positive $(10+\mathrm{mm}$ reactions, or $15+\mathrm{mm}$ with previous $\mathrm{BCG}$ ). Mantoux positivity was not related to age (Table 2 ).

\section{TABLE 2}

MANTOUX TEST RESULTS BY AGE OF INMATES

\begin{tabular}{|lcr|}
\hline Age (years) & No. of inmates & $\begin{array}{c}\text { Positive Mantoux } \\
(\%)\end{array}$ \\
\hline $15-24$ & 20 & $3(15 \%)$ \\
$25-29$ & 18 & $9(50 \%)$ \\
$30-34$ & 31 & $12(39 \%)$ \\
$35-39$ & 30 & $9(30 \%)$ \\
$40-44$ & 17 & $6(35 \%)$ \\
$45+$ & 22 & $8(36 \%)$ \\
Total & 138 & $47(34 \%)$ \\
\hline
\end{tabular}

NB: Mantoux result unknown for one inmate $40-44$ years of age. Age unknown for one Mantoux negative inmate.

Twenty-two (27 per cent) of the 82 Australian-born inmates were Mantoux positive. Nine (64 per cent) of the 14 inmates born overseas were also positive, a significantly increased risk of positivity in overseas-born inmates (relative risk = $2.40 ; 95 \%$ CI 1.41 to 4.07 ). These nine inmates were born in New Zealand, Fiji, Kenya, Lebanon, Papua New Guinea, Sicily, Slovak Republic, Spain and the United States of America. Two of the three known Aboriginal inmates had positive results.

The length of time spent in jail was recorded for 70 inmates, and was not related to Mantoux positivity (Table 3).

\section{TABLE 3}

TIME SPENT IN JAIL BY MANTOUX POSITIVITY

\begin{tabular}{|lrrr|}
\hline Time (years) & \multicolumn{2}{c}{ Mantoux result } & Total \\
& +ve & -ve & \\
\hline 1 & 8 & 18 & 26 \\
$2-4$ & 9 & 15 & 24 \\
$5-7$ & 1 & 7 & 8 \\
$8+$ & 5 & 7 & 12 \\
Not recorded & 24 & 44 & 68 \\
Total & 47 & 91 & 138 \\
\hline
\end{tabular}

Only 15 ( 11 per cent) of the inmates screened reported having had a BCG vaccination. Seventy-seven ( 55 per cent) were known not to have been vaccinated and BCG status was unknown for a further 48 inmates ( 34 per cent). Of the 66 inmates with Mantoux reactions of at least $5 \mathrm{~mm}, 10$ 


\section{Tuberculosis in a NSW jail}

\section{Continued from page 19}

(15 per cent) reported having had a BCG. Only five BCG positive inmates were regarded as having Mantoux positive $(15+\mathrm{mm})$ reactions.

Ten (12 per cent) of the 82 Australian-born prisoners had been vaccinated with BCG. Sixty-eight ( 83 per cent) had not been vaccinated and four prisoners were of unknown BCG status. None of the Aboriginal prisoners had received a BCG. Of the 14 prisoners born overseas, four ( 29 per cent) were known to have been vaccinated.

All the 66 inmates with Mantoux reactions had chest x-rays. These showed clear lung fields in all but one inmate, who had evidence of past lung damage.

Certain other factors influencing health status were examined by interview or by medical chart review.

Thirty-three inmates (24 per cent) had a history of injecting drug use (IDU), 38 ( 27 per cent) were known not to inject drugs and IDU status was unknown for 69 ( 49 per cent). Six injecting drug users had received a BCG. Thirteen ( 39 per cent) had a positive Mantoux test, compared with 29 per cent of non-users.

Twenty-three inmates (16 per cent) had a medical history of alcohol use, while 50 ( 36 per cent) did not and alcohol involvement was unknown for 69 prisoners ( 49 per cent). Six inmates with a history of alcohol use had a positive Mantoux (26 per cent), compared with 36 per cent of nonusers.

All inmates were screened for HIV infection on admission to the jail. None of the 140 prisoners screened was known to have HIV infection or to have an AIDS-defining condition.

Logistic regression modelling showed no significant combined influence of age, BCG status, Aboriginality, length of time in jail, place of birth, injecting drug use and alcohol use on Mantoux positivity.

Of the 20 staff examined, seven ( 35 per cent) were Mantoux positive (two female and five male officers). Both the female officers had 20-29mm Mantoux reactions. One of the male officers had a $10-14 \mathrm{~mm}$ reaction, three had $15-19 \mathrm{~mm}$ reactions and one had a $30+\mathrm{mm}$ reaction. Five of the Mantoux positive officers had had BCGs; all five had $15+\mathrm{mm}$ reactions. All seven officers with a positive Mantoux had clear chest $\mathrm{x}$-rays, with no evidence of TB.

\section{DISCUSSION}

This survey examined the prevalence of TB infection (past and present), associated risk factors and $B C G$ vaccination status in inmates and staff of a NSW jail. The survey was limited by the fact that only half the prisoners were screened and because data were missing on many items for screened inmates. Many of the inmates had been relocated or released before all relevant details were collected so, for some, information had to be gleaned from medical records. Furthermore, the screening was voluntary and it is unknown how representative study subjects were of the general prison population.

Despite these shortcomings, the survey revealed that onethird ( 34 per cent) of screened inmates had been infected with TB at some time in their lives. No information was available to indicate whether infection was atypical TB or not. No active TB cases were found on chest x-ray of Mantoux positive individuals. Fifty-three per cent of positive inmates were known not to have been vaccinated, indicating a high rate of exposure to infection. None of the three known Aboriginal inmates was vaccinated, and two of them were Mantoux positive. Of the 14 prisoners born overseas, nine (64 per cent) were Mantoux positive, and two-thirds were known not to have been vaccinated.

BCG vaccination was associated with Mantoux reactions $(5+m m)$ but not with Mantoux positivity. Overseas origin was significantly associated with Mantoux positivity. There was no association observed with age, alcohol use, length of incarceration or HIV. Logistic regression modelling was inconclusive because of the small sample size and missing details.

Jail inmates often come from the lower socioeconomic strata, have low levels of education and are overrepresented by minority groups. As such, their risk factors for TB infection are high. Despite this, no active cases of TB were found in this screening survey and no TB cases in inmates have been notified to the NSW Health Department since revised notification procedures were introduced in $1991^{5}$. The survey indicates that currently there is a low infection risk in the NSW prison system. This is very different from the situation observed in the US, where TB infection rates in inmates are more than three times higher than in the general population ${ }^{6}$. Although results of this survey are encouraging, the changing spectrum of TB infection - with the rise of drug-resistant TB strains and HIV/TB co-infection - creates a need for continued vigilance. The confined and ever-changing nature of the prison population increases the opportunity for infection, should diseases such as TB be introduced.

Given that groups at risk of TB are known to be overrepresented in the prison population, there is an opportunity for routine screening and follow-up of inmates as a primary health care initiative. This approach would partially address screening recommendations made by the NSW TB Advisory Committee ${ }^{1}$ and also satisfy occupational health and safety concerns of prison staff. It is important that any active TB cases going into the prison system are detected and reported promptly in order for effective public health response to occur. Diagnosis of active disease would precipitate tracing and screening of contacts within the prison population and the general community to prevent the risk of secondary spread.

\section{ACKNOWLEDGMENTS}

David Norris of Grafton Correctional Centre Corrections Health Service coordinated testing and data collection of inmates and staff. Dr Philip Brown, Chief Executive Officer, Corrections Health Service, provided critical comment on the paper.

1. Valway SE, Richards SB, Kovacovich J, Greifinger RB, Crawford JT, Dooley SW. Outbreak of multi-drug-resistant tuberculosis in a New York State prison, 1991. Am J Epidemiol 1994; 140:113-122.

2. Winks M, Levy M, Westley-Wise V. Controlling tuberculosis in New 2. Winks M, Levy M, Westley-Wise V. Controlling tube
South Wales. NSW Health Department, Sydney, 1994 .

3. Bayer R, Dubler NN, Landesman S. The dual epidemics of tuberculosis and AIDS: ethical and policy issues in screening and treatment. Am J of Public Health 1993; 83:649-654.

4. Mantoux test. Circular 94/90. NSW Health Department, Sydney. 5. NSW Infectious Diseases Surveillance System. NSW Health

Department, Sydney.

6. Glaser JB, Greifinger RB. Correctional health care: a public health opportunity. Ann Int Med 1993; 118:139-145. 